\section{Hypothermia, Abdominal Pain, and Lactic Acidosis in Phenformin-treated Diabetic}

\section{British Medical fournal, 1970, 3, 506}

A case of lactic acidosis in a phenformin-treated diabetic is described.

\section{CASe Report}

A 73-year-old man had had a laparotomy in 1962, and subsequently developed an incisional hernia. Primary diabetic symptoms developed in 1964, and he was eventually controlled by diet and phenformin. In February 1967 he was admitted to a surgical ward complaining of abdominal pain, the cause of which was not determined. The rectal temperature on admission was $89^{\circ} \mathrm{F}$. $\left(31.7^{\circ} \mathrm{C}\right.$.) and the blood pressure $105 / 60 \mathrm{~mm}$. Hg. The blood sugar was $80 \mathrm{mg} . / 100 \mathrm{ml}$. and the plasma $\mathrm{CO}_{2} 8.5 \mathrm{mEq} / \mathrm{l}$. His abdominal pain subsided and he was discharged home four days later. In December 1967 the dose of phenformin was increased from 75 to $125 \mathrm{mg}$. daily, in divided doses.

Five days before his present admission he experienced severe abdominal pain but continued to take phenformin and, despite anorexia, was able to celebrate his birthday by consuming six single whiskies. Next day his pain was worse and he vomited twice. The night before admission he remained in bed in a room heated by a coal fire. The minimum temperature in Aberdeen on that night was $39.9^{\circ} \mathrm{F} .\left(4.4^{\circ} \mathrm{C}\right.$. $)$.

On admission he was confused, dehydrated, and in pain. His face was puffy, his voice was husky, and respirations were rapid and deep. The rectal temperature was $80^{\circ} \mathrm{F}$. $\left(26.7^{\circ} \mathrm{C}\right.$.), pulse 60 per minute, and blood pressure 100/55. Tenderness was present in the right iliac fossa and the bowel sounds were slightly reduced. The pupils were unequal and dilated, and did not react to light. No plantar response could be elicited.t.Urine contained traces of sugar and ketones. The blood chemistry and blood gas analysis on admission and during treatment are shown in the Table. The initial blood sugar? was $202 \mathrm{mg} . / 100 \mathrm{ml}$., the blood

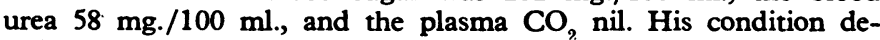
teriorated and he became comatose with an unrecordable blood pressure. Soon after admission lactic acidosis was confirmed and the calculated "excess lactate" was $10 \mathrm{mEq} / \mathrm{l}$. At the same time the plasma acetoacetate was $0.24 \mathrm{mmole} / \mathrm{l}$., and the plasma $\beta$ hydroxybutyrate $2.37 \mathrm{mmole} / \mathrm{l}$. The E.C.G. showed a sinus bradycardia with diffuse $T$-wave flattening. $J$-waves (Osborn waves) were not present. The P-R interval was 0.24 second, the Q-T interval 0.52 second, and the bases of the QRS complexes were widened. The conduction defects reverted to normal on the next day.
A total of $1,200 \mathrm{mEq}$ of sodium bicarbonate and 4 litres of $5 \%$ dextrose in water was given by intravenous infusion during the first 18 hours. Small doses of soluble insulin were given in an attempt to control hyperglycaemia. The rectal temperature returned to normal in 18 hours. The blood pressure rose to normal levels as hypothermia and acidosis improved. The day after admission he was rational, able to take oral fluids, and had no abdominal pain.

\section{Comment}

Attention has been drawn to the association of lactic acidosis with diabetes mellitus, and diabetic patients who have been treated with phenformin seem to be particularly prone to this condition (Tranquada et al., 1963).

One of the interesting features of the above case is the hypothermia. Accepted causes of hypothermia were excluded, but alcohol may have contributed in this case, and it has been shown to increase blood lactate levels in normal subjects (Lieber and Davidson, 1962), and in diabetics taking phenformin (Johnston and Waterhouse, 1968). In the absence of other causes the hypotension in this patient may be explained on the basis of hypothermia and dehydration.

Investigations did not reveal any cause for this patient's abdominal pain, which has been described in severe diabetic ketoacidosis but not as part of the clinical picture of lactic acidosis. One remarkable feature of the present case was the episode of abdominal pain, hypothermia, and acidosis occurring almost a year previously. It seems that otherwise unexplained abdominal pain and hypothermia may be common accompaniments of the syndrome of lactic acidosis, particularly those cases associated with phenformin therapy.

We wish to thank Professor A. G. Macgregor and Dr. J. M. Stowers for allowing us to publish details of this case.

\section{G. G. SHIRRIFFS,* M.B. CH.B. \\ P. D. BEWSHER, M.B., M.R.C.P.ED.} \section{Department of Therapeutics and Pharmacology,
University of Aberdeen.}

* Now General Practitioner, Aberdeen.

\section{REFERENCES}

Johnston, H. K., and Waterhouse, C. (1968). American fournal of Medicine, 45, 98.

Lieber, C. S., and Davidson, C. S. (1962). American fournal of Medicine, 33, 319

Tranquada, R. E., Bernstein, S., and Martin, H. E. (1963). fournal of the American Medical Association, 184, 37.

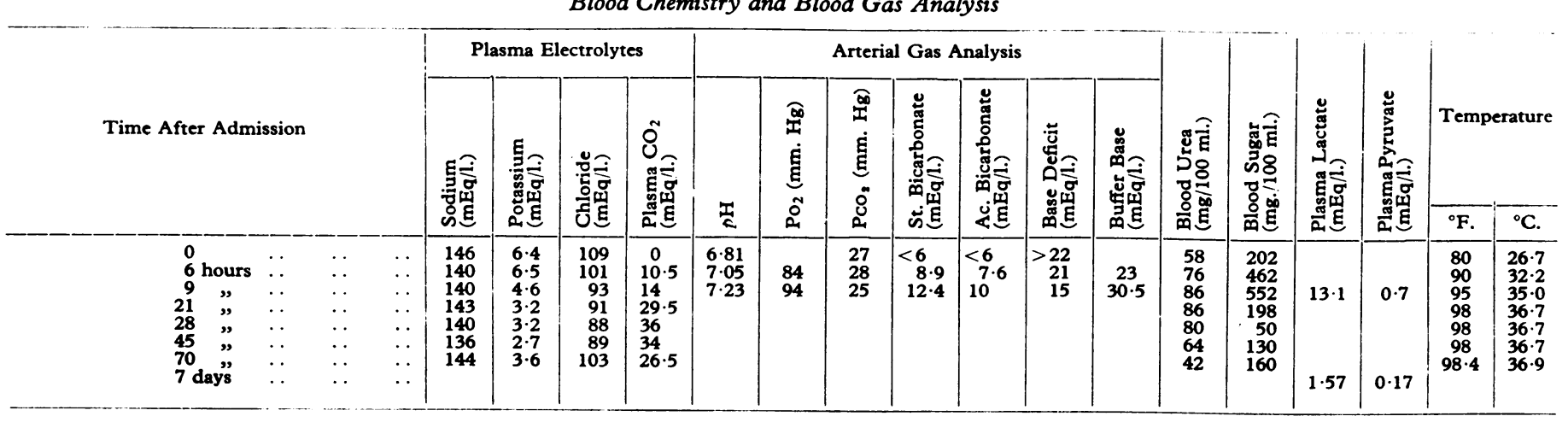

